\title{
Desigualdade racial nos espaços escolares e o trabalho do assistente social
}

\section{Racial inequality in school and the work of social worker}

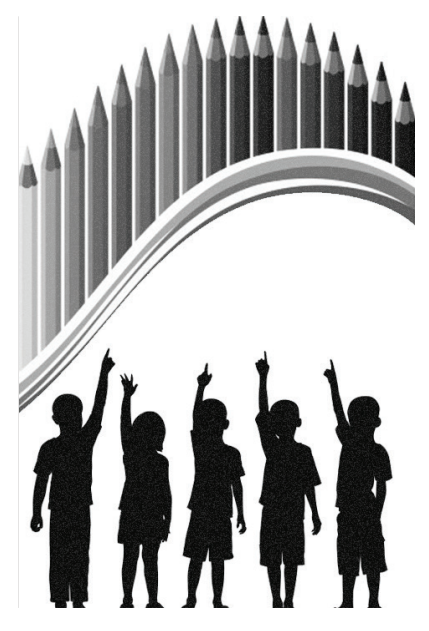

\author{
Tais Pereira de Freitas* \\ Helen Barbosa Raiz Engler**
}

Resumo: O texto ora apresentado enfoca a reflexão acerca dos rebatimentos da desigualdade racial nos espaços do sistema educacional, que se configuram fundamentais, tanto para a reprodução, quanto para o enfrentamento da condição desigual. Dessa forma, considera-se o potencial da escola para o processo de construção da igualdade racial e o compromisso ético do Serviço Social na construção de outra ordem societária, buscando-se discutir as contribuições da inserção do assistente social na política pública de educação.

Palavras-chave: Desigualdade racial. Política pública de educação. Serviço Social.

\begin{abstract}
The text presented here focuses on the reflection on the repercussions of racial inequality in the spaces of the educational system that are configured crucial both for reproduction and for coping with the uneven condition. Thus it is considered the potential for the school construction process of racial equality and ethical commitment of social work in building a other social order, seeking to argue the role of the social worker integration in public education policy.
\end{abstract}

Keywords: Racial inequality. Public education policy. Social Work.

* Assistente social, mestre e doutoranda em Serviço Social pela Faculdade de Ciências Humanas e Sociais, Universidade Estadual Paulista "Júlio de Mesquita Filho", Unesp, Franca/SP, Brasil. E-mail: taispfreitas@hotmail.com.

** Professora doutora do Departamento de Serviço Social e do Programa de Pós-Graduação em Serviço Social da Faculdade de Ciências Humanas e Sociais, Unesp, campus de Franca/SP, Brasil. E-mail: helenraiz@hotmail.com. 


\section{Introdução}

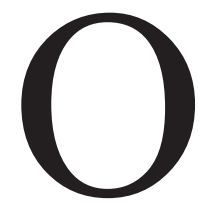

presente texto, elaborado a partir de construções teóricas que serão apresentadas em tese de doutorado, propõe a discussão acerca das contribuições do assistente social no enfrentamento da questão racial, expressão da questão social, dentro dos espaços escolares.

O processo de constituição socioeconômica, política e cultural do Brasil, intrinsecamente relacionado ao desenvolvimento do sistema do capital, implica particularidades, relacionadas especialmente à formação de uma colônia de exploração mercantil no país. A invasão dos portugueses ao território, até então ocupado pelas inúmeras tribos indígenas, é parte da estratégia para conquista do mercado e desenvolvimento do capital mercantil na esfera internacional.

Essa análise é bastante cara para a reflexão aqui proposta, uma vez que a sociedade escravista que se forma no Brasil tem caráter mercantil e, portanto, o seu desenvolvimento e sua decadência estão diretamente relacionados aos ciclos de expansão/retração do sistema capitalista. Mesmo com a abolição oficial do sistema escravista permaneceram elementos característicos dessa configuração, o que vai contribuir para a permanência (reconfigurada por vezes) do quadro de desigualdade racial que vulnerabiliza, explora e oprime a população negra no Brasil. Tal processo de exploração/opressão caracteriza as relações capitalistas de produção.

Tem-se um sistema que se funda sob as bases da acumulação e, portanto, as instituições da sociedade fundada sob essa orientação comprometem-se para assegurar ou legitimar essa ordem. A escola (todos os níveis de ensino formalizado) é emblemática para esse entendimento, uma vez que se constitui como uma das instituições privilegiadas para a formação de quadros que assegurem o fortalecimento do capital, tanto aqueles detentores dos meios de produção, quanto os trabalhadores que serão expropriados no processo de produção da riqueza. Dentro dessa lógica, na trajetória histórica da política de educação brasileira é possível identificar uma escola para a classe que detém os meios de produção e outra para a classe que vive do trabalho.

Contudo, dialeticamente, a escola pode ser também o espaço para as ações com vistas à transformação do que está posto e particularmente, conforme enfocado neste texto, para o enfrentamento da desigualdade racial. 
Nesse contexto, é possível destacar a inserção do assistente social nos espaços escolares, processo em curso no país e que, na análise aqui discutida, irá contribuir no enfrentamento proposto, na medida em que a profissão tem como um de seus compromissos éticos a defesa de um projeto societário que aponta para a construção de outra ordem societária, sem exploração/opressão de classe, gênero, raça e etnia. Dessa forma, a partir de suas competências ético-políticas, teórico-metodológicas e técnico-operativas, os profissionais de Serviço Social podem contribuir significativamente para o trabalho de promoção da igualdade racial dentro dos espaços escolares.

Partindo desses pressupostos iniciais, o texto ora apresentado busca analisar brevemente o processo histórico da desigualdade racial no Brasil e seus rebatimentos no sistema educacional, para apontar a escola enquanto instituição reprodutora da desigualdade, mas também, dialeticamente, espaço privilegiado para o enfrentamento e, nessa análise, destacando-se a inserção profissional do assistente social enquanto agente no fortalecimento desse processo.

\section{Desigualdade racial no Brasil: a escola e o reflexo desse panorama}

A desigualdade racial no Brasil pode ser visualizada na contemporaneidade a partir de diversas dimensões, entre elas, o acesso à educação. A situação de vulnerabilidade vivenciada pela população negra tem no âmbito do acesso e permanência no sistema educacional uma de suas expressões mais significativas. Considerando inicialmente a dimensão da alfabetização, segundo dados sistematizados no relatório anual das desigualdades raciais no Brasil 2009-2010 (Paixão, 2010, p. 207), em 1988 a taxa de analfabetismo entre a população branca acima de 15 anos era de $12,1 \%$, e em 2008 passa a ser de $6,2 \%$. Entre a população negra acima de quinze anos, essa taxa era de $28,6 \%$ em 1988, e em 2008 passa a ser de $13,6 \%$. Ou seja, mesmo diante de considerável avanço, a taxa de analfabetismo da população negra em 2008 ainda é maior do que a registrada entre a população branca em 1988.

Ampliando a análise para os anos de estudos, o mesmo relatório aponta que em 2008, entre os homens brancos com mais de quinze anos de idade, a média de anos de estudo foi de 8,2 , enquanto entre os homens pretos e pardos 
com mais de quinze anos de idade, a média de anos de estudo foi de 6,3. Já entre as mulheres na mesma faixa etária, a média de anos de estudo foi de 8,3 entre as brancas e 6,7 entre as negras (pretas e pardas).

Esse panorama contemporâneo não pode, contudo, ser percebido descolado do processo de formação econômica, cultural, social e política do país, que remete ao modo de produção escravista mercantil, essencial para o desenvolvimento da colônia Brasil, mas que se insere também entre os pré-requisitos da eclosão capitalista modernizadora (Fernandes, 2011, p. 363).

De acordo com a análise de Fernandes (2011) a ocupação do território (que depois passa a ser chamado de Brasil) por Portugal deu-se não pela necessidade de povoar, mas antes pela premência de produzir, já que a escravidão colonial dava suporte material ao capitalismo comercial na Europa. Tal escravidão é caracterizada principalmente por ser mercantil, ou seja,

[...] o escravo não só constitui uma mercadoria; é a principal mercadoria de uma vasta rede de negócios (que vai da captura e do tráfico de escravos e à forma de trabalho), a qual conta, durante muito tempo, como um dos nervos ou a mola mestra da acumulação do capital mercantil. (Fernandes, 2011, p. 365)

Identifica-se uma formação onde a colônia (Brasil) é parte do sistema econômico da metrópole (Portugal), mas também de toda a rede de centros econômicos mundiais da época (Inglaterra, por exemplo) e, nessa análise, o proprietário do escravizado não era o detentor exclusivo do excedente gerado pelo trabalho. Tal excedente entrava no sistema de apropriação do capital mercantil, constituído por dimensões não apenas econômicas, mas legais, políticas e fiscais. Mesmo sendo o escravizado "propriedade econômica do senhor", a escravidão mercantil não era um "negócio privado", mas tinha como finalidade produzir e reproduzir rendimentos econômicos gerados nas transações comerciais. A esses rendimentos, Fernandes (2011) denomina butim, cujo significado remete aos bens materiais tomados de escravos ou prisioneiros durante um ataque ou guerra, ou ainda o resultado de um roubo, de uma pilhagem.

Esse butim, no plano em que se dava a partilha colonial dos frutos da pilhagem, perdia qualquer ligação com suas origens. Aí, nem a produção escravista nem a 
propriedade do senhor contavam para qualquer efeito. O que importava eram as "mercadorias" e as "riquezas" que entravam, através desse singular rateio — provavelmente o mais odioso tipo de pilhagem da história humana — na circulação engendrada pelo capital mercantil (Fernandes, 2011, p. 373).

Com a transição do período colonial (onde se constituem as bases para a formação de um capitalismo dependente no Brasil), a escravidão mercantil continua a existir, porém os senhores agora têm como desafio adequar a força de trabalho escravo às configurações das formas de produção, que já não se limitavam às plantações. Esse desenvolvimento econômico, ao mesmo tempo em que dependente do sistema escravista, traz também a necessidade de outras formas de trabalho, contribuindo para a desagregação do sistema que existia e que até então havia possibilitado a formação da riqueza da colônia e, principalmente, do Império, cumprindo a função de fator de acumulação de capital.

Historicamente, esse fator tornou-se ineficaz, sendo substituído por formas de acumulação mais apropriadas e rentáveis ao desenvolvimento do capital, o que vai "condenar" a escravidão mercantil ao desaparecimento (Fernandes, 2011, p. 420-421).

Entre os elementos que se destacam nessa análise, é possível apontar que a escravização da população negra no Brasil não apenas serviu, mas foi ainda fundamental, para o desenvolvimento do sistema capitalista no país e que, portanto, as desigualdades apontadas anteriormente constroem-se e reconstroem-se dentro e intrinsecamente relacionadas a tal sistema.

Nesses termos, o enfrentamento da desigualdade racial na peculiaridade brasileira precisa ser compreendido no contexto de superação da ordem social vigente, assentada sobre as bases do capital, e as ações a serem desenvolvidas são sempre possibilidades presentes, remetendo a um projeto macro de construção de outra ordem societária. Assim, não são apenas ações culturais, sociais, mas econômicas e políticas, estando imbricadas no ideário de transformação da realidade que está posta.

Tal construção articula-se às mais diversas e amplas lutas sociais, e é a partir do horizonte ético da emancipação que acreditamos na contribuição que pode se originar no contexto da escola, compreendida na perspectiva da concepção 
de Gramsci (Nosella, 2010) como instituição responsável pelo ensino formal e que, nesse texto, refere-se à escola pública (em todos os níveis) dirigida pelos pressupostos da política pública de educação.

A concepção de escola que possibilita a reflexão acerca da igualdade racial é aquela onde a educação não é puramente tecnicista, utilitária, ou, citando Gramsci (apud Nosella, 2010, p. 50), uma "escola interessada".

Trata-se antes de uma "escola desinteressada", integrada, unitária, onde apreende-se tanto aspectos gerais do desenvolvimento da vida em sociedade (cultura geral), quanto preparação para o mercado de trabalho. Ou seja, não se trata da negação pura e simples da escola técnica, aquela destinada a preparar para o mercado de trabalho, mas antes da necessidade de que essa escola se construa na unidade, na integração entre espaço escolar e realidade objetiva.

Todavia, o que é possível apontar é a existência de uma dicotomia entre o que se trabalha através do currículo escolar e a realidade concreta dos educandos. Tal cisão é sobremodo evidente na escola brasileira. A formação histórico-cultural do país, assentada sobre o entendimento da superioridade de uns sobre outros, transforma a riqueza da diversidade em abismal desigualdade, e nesse horizonte, a narrativa histórica exclui e/ou torna invisíveis aqueles de quem é tirado o direito de expressar-se e contar a história da qual foram parte, para qual contribuíram, e que só é assim porque eles dela participaram.

No Brasil, em todas as dimensões de sua constituição de nação, estão presentes aspectos fundamentais das culturas que compuseram essa gente, esses costumes, essa língua portuguesa cheia de milongas, calundus, batuques, abacaxis e torós. Nesse território desenvolve-se uma forma de civilização que, ainda que buscasse copiar a metrópole, não era extensão de Portugal; mesmo com o elevado número de africanos, não era um "pedacinho de África", e também já não era mais a terra milenarmente ocupada pelos indígenas.

A partir dessa análise, e considerando inicialmente as influências africanas, indígenas e portuguesas, apontar no Brasil apenas uma delas como preponderante é desconsiderar todo o complexo sobre o qual foram tecidas as cores e formas desta sociedade. A história repetida nas versões oficiais relega indígenas e africanos a segundo plano, confina os homens africanos às lavouras "do lado de fora", e as mulheres "às cozinhas", como se indígenas e africanos houvessem 
apenas dado "uma contribuição" para a formação brasileira, e não efetivamente povos que contribuíram para que o Brasil fosse desse jeito e não de outro.

Além disso, essa história assim contada e recontada reduz toda a diversidade étnica das inúmeras tribos que habitavam o país a uma única denominação, os "índios", e todas as nações africanas trazidas forçadamente para o Brasil como os "escravos".

Havia no continente africano uma multiplicidade cultural significativa, e mesmo entre os africanos trazidos para o Brasil havia inúmeros dialetos, culturas, religiões. Reduzir essa riqueza à denominação única de "escravos africanos" é a primeira demonstração do quanto a presença negra foi compactada, desfocada e diminuída na história do país.

Tal desfoque é evidenciado no currículo escolar, que privilegia a "história oficial" e, portanto, não negra e não indígena. O que se tem assistido no Brasil é a constituição de uma escola (desde a pré-escola até a universidade) para a "classe que vive do trabalho" e a continuidade daquela destinada a classe historicamente detentora dos meios de produção.

Na crítica de Gramsci (apud Nosella, 2010, p. 50) é preciso a escola desinteressada, aquela que permite o desenvolvimento integral do educando, ou seja,

uma escola que dê à criança a possibilidade de se formar, de se tornar homem, de adquirir aqueles critérios gerais necessários para o desenvolvimento do caráter. Uma escola humanista, em suma, assim como a entendiam os antigos e mais próximos homens do Renascimento. Uma escola que não hipoteque o futuro do garoto, nem obrigue sua vontade, sua inteligência, sua consciência e informação a se mover na bitola de um trem com estação marcada. Uma escola de liberdade e livre-iniciativa, e não uma escola de escravidão e de mecanicidade.

Essa é a concepção de escola que contempla a igualdade racial e mais, apenas nessa escola é possível essa construção. $\mathrm{O}$ educando deve ter acesso a saberes que the permitam situar-se no mundo de forma que, as relações estabelecidas estejam assentadas sob o ideário humanista e, assim, intrinsecamente relacionadas à igualdade. 
Todavia, essa proposta não pode ser limitada a uma ou outra instituição de ensino que resolva adotar um currículo diferenciado, ou mesmo cumprir efetivamente dispositivos legais como a Lei n. 10.639, de 9 de janeiro de 2003, que estabelece a obrigatoriedade da temática "História e cultura africana" no currículo oficial da educação no Brasil. Tal concepção de escola só se efetiva enquanto elemento de transformação da realidade que está posta a partir da primazia da responsabilidade do Estado na condução dessas ações. Ou seja, torna-se necessário uma política pública de educação que contemple em sua formulação, implementação, execução e avaliação, aspectos que remetam à igualdade racial.

Sem a pretensão de oferecer respostas ou medidas prontas para serem implementadas, a proposta deste texto é a busca por refletir sobre possibilidades e caminhos a serem construídos a partir da escola, e é nesse sentido que a inserção do assistente social na política pública de educação pode possibilitar algumas trajetórias.

\section{Igualdade racial e a inserção do Serviço Social na política pública de educação no Brasil}

A proposta de educação que possibilite o enfrentamento da desigualdade racial remete à reflexão acerca das significações do conceito de igualdade na sociedade que se constitui sobre os fundamentos do modo de produção capitalista. Não se trata da igualdade cujo propósito maior seja permitir que todos consumam igualmente. Trata-se antes do entendimento de que todos os seres humanos têm direitos iguais, e devem ser asseguradas condições objetivas para que possam acessar e usufruir desses direitos.

Igualdade deveria constituir-se, dessa forma, princípio para a vida social, mas é possível observar que, historicamente, foi se transfigurando e reduzindo-se apenas à busca de garantia para condições iguais de consumo. A reflexão acerca da necessidade de uma política de educação para igualdade assenta-se sobre a perspectiva do acesso e usufruto de direitos, que são comuns a todos os seres humanos, mas que na sociedade contemporânea estão acessíveis a alguns e inalcançáveis para outros, o que objetivamente torna aqueles que têm acesso aos direitos, "sujeitos sociais", e aqueles que não os têm, invisíveis. 
O processo histórico cultural de formação da sociedade brasileira, as configurações do modo de produção capitalista, as transformações ocorridas no mundo do trabalho, entre outras dimensões, contribuem para a construção do que denomina-se desigualdade racial, que no país desprivilegia a população negra, mesmo que a vigente Constituição da República Federativa do Brasil estabeleça que todos são iguais.

A igualdade estabelecida na lei não existe de fato, o que implica o processo histórico de exclusão de determinados segmentos da população do direito de participação, de decisão ou, ainda, da liberdade, entendida minimamente como possibilidade concreta de escolha.

A instituição da escola no Brasil é um processo marcado, desde suas origens, pela desigualdade, que também historicamente se visualiza no país. Tem-se como marco do processo de sistematização da oferta de ensino no Brasil a presença dos jesuítas através da Companhia de Jesus, que em 1570 já contava com cinco escolas de nível elementar e três de nível médio, perfazendo oito estabelecimentos de ensino, voltados exclusivamente para a educação dos homens e com o direcionamento para o sacerdócio ou a advocacia (Cotrim e Parisi, 1982, p. 260).

A partir da segunda metade do século XVIII, com o avanço dos ideais do Iluminismo por toda a Europa, Portugal busca modernizar a aprendizagem tanto nas metrópoles quanto nas colônias. Assim, torna o ensino mais utilitário, buscando diminuir o direcionamento da Companhia de Jesus, o que implicou a expulsão dos jesuítas dos domínios de Portugal em 1759.

Todavia, no Brasil, efetivamente não alterou o panorama educacional, visto que a estrutura da Companhia de Jesus já estava solidificada no país, e Portugal não ofereceu nenhuma outra proposta significativa, permanecendo o sistema educacional sem grandes alterações durante todo o período imperial. Cotrim e Parisi (1982, p. 267) destacam:

Era uma educação de fachada, ornamental, acadêmica, desvinculada da realidade social. A instrução era apenas uma forma de demonstração de status, servindo, quando muito, para auxiliar a ascensão do indivíduo ao exercício da atividade política. 
O processo da Revolução de 1930, na esteira da Proclamação da República em 1889, marca a história do Brasil, visto que a partir dele muda-se de forma profunda e definitiva a face do país, que nesse período inicia sua transição de uma sociedade predominantemente agrária para uma nação industrial e moderna (Aggio, Barbosa e Coelho, 2002, p. 16).

Destaca-se nesse período a criação do então Ministério da Educação e Saúde (1937) e a difusão dos novos ideais para a educação, particularmente por meio das Constituições federais de 1934 e 1937, que asseguraram que os brasileiros tinham o direito a receber pela família e poder público, a educação "elementar" e o ensino técnico e profissionalizante.

A ampliação das vagas nas escolas com a progressiva expansão dos níveis de ensino constitui processo em curso no país, especialmente a partir dos anos 1980, no período pós-ditadura militar, quando se busca assegurar para todas as crianças brasileiras o acesso à escola, oportunizando inclusive condições objetivas para tal, como merenda escolar, livro didático. A partir de meados da década de 1990 pode-se verificar que essa "preocupação" estende-se também para os adolescentes, no sentido de garantir a ampliação dos anos de estudo para a população brasileira. E finalmente, a partir dos anos 2000, é possível observar que amplia-se o acesso ao ensino superior, principalmente pela expansão das instituições privadas de ensino, bem como a implementação de programas estatais para garantia de acesso à universidade (sobretudo às instituições privadas) para jovens oriundos de famílias de baixa renda.

Todavia, essa ampliação do acesso a todos os níveis de ensino formal no Brasil leva às indagações acerca da qualidade dessa oferta. Ou seja, buscou-se ampliar o número de vagas, mas um dos questionamentos é se esse crescimento foi acompanhado da qualidade do ensino ou se foram reduzidos os investimentos em qualificação profissional, material de apoio, condições físicas das salas de aula, para garantir apenas o aumento do número de vagas.

O que significou a ampliação das oportunidades de acesso? É preciso pensar que por vezes, sob o discurso da garantia de maior número de vagas, reduziram-se os investimentos nas demais dimensões, o que implicou a queda significativa da qualidade do ensino. 
Contudo, a reflexão acerca da qualidade na educação não se limita ao aspecto da ampliação do número de vagas. Os comparativos (quase sempre assentados sob a perspectiva do senso comum) nos quais busca-se cotejar a educação formal ofertada na contemporaneidade, com aquela de décadas atrás, acabam por incorrer no erro de não considerar o processo histórico onde se insere a educação formal no Brasil. Nas décadas de 1970, 1980, propunha-se uma educação que desse conta da demanda da sociedade daquele período, e esperar ou propor a educação naqueles mesmos moldes, muito mais que um saudosismo deslocado, implica uma leitura com equívocos significativos.

O processo de modernização vivenciado na sociedade brasileira (em todas as suas dimensões) não comporta os moldes de educação das décadas passadas. Por outro lado, não se encontram alternativas/propostas para a oferta de um sistema de educação que garanta oportunidades iguais de desenvolvimento, de construção de cidadania, de entendimento do humano para além da perspectiva utilitarista. Daí a necessidade da compreensão da amplitude do significado de construção da igualdade na contemporaneidade e que no espaço da escola é demasiadamente complexa e ampla para limitar-se às relações entre educador e educando, ao lócus exclusivo da sala de aula.

O espaço escolar enquanto possibilidade para a igualdade racial não pode limitar-se à ação desses dois agentes (educador e educando), podendo e devendo ser ampliado e aberto para a contribuição de outras áreas, entre elas o Serviço Social.

A inserção do Serviço Social no contexto da escola no Brasil pode ser discutida dentro da concepção da política pública de educação, e essa reflexão não é recente no âmbito da profissão. Contudo, ganha destaque apenas a partir do início de 2000, com a elaboração de pareceres, formação de comissões para estudos e reflexões, grupos de trabalho, além da realização do Seminário Nacional de Serviço Social na Educação (2012) e da elaboração do documento intitulado Subsídios para a atuação de assistentes sociais na política de educação (CFESS, 2012).

No espaço da política pública de educação, os assistentes sociais devem atuar em consonância com o projeto ético-político da profissão, na defesa da igualdade, princípio fundamental para a proposta emancipatória defendida pelo Serviço Social. 
Conforme Martins (2012, p. 45), o trabalho profissional do Serviço Social nos espaços da política pública de educação ocorre a partir de três eixos: a dimensão socioeducativa da profissão, a democratização da educação e a articulação entre essa política e as demais. $\mathrm{Na}$ análise aqui proposta, ganha destaque a dimensão socioeducativa do trabalho do Serviço Social, uma vez que o profissional, a partir desse aspecto, pode de forma efetiva intervir no processo de enfrentamento da desigualdade racial.

O assistente social na Educação poderá atuar com todos os membros da comunidade escolar, tendo a possibilidade de mobilizar um processo reflexivo que envolve a percepção objetiva da vida social, e da vida de cada indivíduo e das condições sociais e históricas que norteiam a sociedade. Esta atividade propicia a politização em torno de diversos temas que perpassam o ambiente escolar e social (Martins, 2012, p. 46).

A mobilização para a reflexão, apontando para a percepção das condições sociais e históricas, conforme destaca Martins no trecho citado, indica, em nossa percepção, as possibilidades para as contribuições do trabalho do assistente social no processo de enfrentamento da desigualdade racial no espaço da escola. É nesse processo de mobilização, reflexão e politização que o Serviço Social constrói as estratégias para o enfrentamento da questão racial (expressão da questão social, objeto de trabalho da profissão) no ambiente escolar, que se configura enquanto espaço reprodutor da desigualdade, mas também lócus privilegiado para a negação dessa realidade e construção do novo.

Nessa dimensão, a proposta de educação que orienta a práxis dos assistentes sociais não pode ser aquela que reproduz as relações sociais presentes na sociedade, mas, antes, uma educação orientada para a promoção do ser humano enquanto sujeito coletivo.

A educação pode ser considerada um espaço privilegiado para o enriquecimento ou empobrecimento do gênero humano. Assim, na perspectiva de fortalecimento do projeto ético-político, o trabalho do/a assistente social na política de educação pressupõe a referência a uma concepção de educação emancipadora, que possibilite aos indivíduos sociais o desenvolvimento de suas potencialidades e capacidades como gênero humano (CFESS, 2012). 
Com esse direcionamento, o profissional de Serviço Social, ao inserir-se nos diferentes espaços sócio-ocupacionais que demarcam os diversos níveis e modalidades de ensino, no âmbito da política de educação, deve voltar-se para a garantia da qualidade que vai além de estratégias para permanência na escola, diminuição de índices de repetência, mesmo de alfabetização formal.

A qualidade da educação defendida pelo Serviço Social está intrinsecamente relacionada com a construção de outra ordem societária e, portanto, não pode prescindir do compromisso profissional do assistente social com a emancipação, enquanto demanda política inerente a liberdade, valor ético central, conforme preconiza o Código de Ética Profissional.

A qualidade da educação, aqui referida, ao mesmo tempo em que envolve uma densa formação intelectual com domínio de habilidades cognitivas e conteúdos formativos, também engloba a produção e disseminação de um conjunto de valores e práticas sociais alicerçadas no respeito à diversidade humana e aos direitos humanos, na livre orientação e expressão sexual, na livre identidade de gênero, de cunho não sexista, não racista e não homofóbica/lesbofóbica/transfóbica, fundamentais à autonomia dos sujeitos singulares e coletivos e ao processo de emancipação humana (CFESS, 2012).

A escola no Brasil que visa à qualidade não pode, considerando as peculiaridades de formação do país, abrir mão do trabalho que objetive o enfrentamento da desigualdade racial e que aponta para a emancipação humana. O trabalho profissional do assistente social relaciona-se a esse compromisso qualitativo, na medida em que, comprometido com o projeto ético-político da profissão, caminha na construção de outra ordem societária. No âmbito da discussão proposta neste texto, considera-se fundamental a inserção do Serviço Social na política pública de educação, assegurando as condições necessárias para que se desenvolva uma proposta de articulação dos diversos atores do lócus escolar.

Pensar o trabalho profissional nesse espaço e com esse direcionamento requer o questionamento acerca das competências profissionais, uma vez que o trabalho profissional deve estar comprometido com a defesa intransigente dos direitos humanos e a recusa do arbitrio e do autoritarismo. 
Esse compromisso requer a defesa do aprofundamento da democracia, enquanto socialização da participação política e da riqueza socialmente produzida; o posicionamento em favor da equidade e justiça social, assegurando a universalidade de acesso os bens e serviços relativos aos programas sociais, bem como sua gestão democrática. Esses princípios destacados levam à reflexão acerca do compromisso ético-profissional, que não é diferenciado no lócus da política pública de educação e que pressupõem competências que se relacionam às dimensões teórica, técnica, ética e política do trabalho profissional, desenvolvidas mesmo no cenário de determinações colocadas pelas configurações atuais do sistema do capital e seus rebatimentos nas relações não apenas econômicas, mas também sociais, políticas e culturais.

Segundo Iamamoto (1998), a realidade atual da globalização, a alteração das relações entre Estado e sociedade civil, o agudizamento da questão social em suas múltiplas manifestações provocam a profissão para a intervenção crítica frente à realidade. Assim, o Serviço Social encontra-se às voltas com o desafio de desenvolver o trabalho profissional articulado às atuais configurações da sociedade, o que significa ampliar também os espaços para a práxis profissional transformadora, entre eles o lócus escolar.

Considerando que o trabalho profissional do assistente social desenvolve-se nessa realidade que se modifica constantemente, ele só tem sentido na história da sociedade na qual está inserido, sendo que "pensar o Serviço Social na contemporaneidade requer os olhos abertos para o mundo contemporâneo para decifrá-lo e participar de sua recriação" (Iamamoto, 1998, p. 19). As transformações ocorridas e ainda em curso na realidade brasileira exponenciam o desafio de decifrar a realidade para nela intervir de forma crítica, colocando para o Serviço Social, enquanto categoria profissional comprometida com a transformação social, a necessidade de cada vez mais desenvolver seu trabalho de forma radicalmente articulada com as demandas da contemporaneidade.

Dessa forma, delineia-se o trabalho do assistente social inserido na política pública de educação e que pode ter, como uma das dimensões de sua intervenção, ações direcionadas para o enfrentamento da desigualdade racial, assentadas sob a perspectiva da emancipação humana em uma análise que entende os limites de tal construção na ordem societária burguesa vigente, mas que também visualiza as possibilidades que tal ação representa. 
Emancipação configura-se assim como necessidade, ponto de partida/ chegada no processo de construção da ordem societária com valores distintos do capital, na medida em que potencializa protagonismos sociopolíticos dos sujeitos em condição de subalternidade. Trata-se ainda da necessidade de instituição de outros padrões éticos para a vida em sociedade, de valores que estejam fundamentados na condição humana como elementos essenciais para a construção de projetos societários.

Para o Serviço Social evidencia-se, portanto, a necessidade de se garantir direitos, implementar políticas, desenvolver ações que tenham como compromisso a alteração do quadro de relações raciais desiguais. Esse é um dos compromissos expressos no projeto ético-político da profissão e que encontra no espaço das instituições escolares possibilidades de intervenção frente à realidade.

Conforme destacado em Subsídios para atuação de assistentes sociais na política pública de educação (CFESS, 2012), a educação configura-se como elemento essencial na construção de uma sociedade justa e igualitária, defendida pelo Serviço Social. Todavia, tem sido historicamente utilizada para a manutenção da ordem hegemônica do capital, mas pode também servir de estratégia para possibilitar a contra-hegemonia, e é nesse contexto que o Serviço Social encontra os elementos para desenvolver sua práxis profissional, que, conforme apontado nesse texto, pode contribuir para o enfrentamento da desigualdade racial.

\section{Conclusão}

A aproximação do Serviço Social com a política pública de educação não é recente, podendo-se apontar que, desde a sua institucionalização, a profissão está tanto inserida nos espaços escolares (ainda que de início voltada para a prática assistencialista), como participando das discussões e movimentos para elaboração, implementação e execução da referida política. Contudo, é a partir dos anos 2000 que o Serviço Social passa a discutir de forma mais efetiva a inserção profissional do assistente social na política pública de educação.

Dessa forma, é possível apontar avanços significativos na reflexão que a categoria profissional de assistentes sociais vem construindo acerca da inserção 
nessa política pública. Todavia, é preciso ressaltar que a trajetória de consolidação da educação, enquanto política pública, é ainda repleta de avanços e retrocessos.

É nessa trajetória de conquistas e limitações da política de educação que se insere a discussão acerca do enfrentamento da desigualdade racial e o trabalho do assistente social. Pensar essa construção é, portanto, necessidade da sociedade brasileira como está constituída na contemporaneidade e que dessa forma deve estar presente nas propostas que se relacionam com a política pública de educação.

Recebido em 29/7/2014 - Aprovado em 24/11/2014

\section{Referências bibliográficas}

AGGiO, A.; BARBOSA, A. S.; COELHO, H. M. F. Politica e sociedade no Brasil (1930-1964). São Paulo: Annablume, 2002.

COTRIM, G. V.; PARISI, M. Fundamentos da educação: história e filosofia da educação. 6. ed. São Paulo: Saraiva, 1982.

CFESS ( Conselho Federal de Serviço Social). Subsídios para a atuação dos assistentes sociais na política de educação. Brasília: CFESS, 2012.

FERNANDES, F. A sociedade escravista no Brasil. 1976. In: IANNI, O. (Org.). Florestan Fernandes: sociologia crítica e militante. 2. ed. São Paulo: Expressão Popular, 2011.

IAMAMOTO, M. V. O Serviço Social na contemporaneidade: trabalho e formação profissional. São Paulo: Cortez, 1998.

MARTINS, E. B. C. O Serviço Social no âmbito da política educacional: dilemas e contribuições da profissão na perspectiva do projeto ético político. In: SILVA, M. M. J. (Org.). Serviço Social na educação: teoria e prática. Campinas: Papel Social, 2012.

NOSELLA, P. A escola de Gramsci. 4. ed. São Paulo: Cortez, 2010.

PAIXÃO, Marcelo et al. Relatório anual das desigualdades raciais no Brasil 2009-2010. Rio de Janeiro: Garamond, 2010. 